\title{
Why do some overweight children remain overweight, whereas others do not? $\dagger$
}

\author{
Youfa Wang ${ }^{1, *}$, Keyou Ge ${ }^{2}$ and Barry M Popkin ${ }^{3}$ \\ 'Department of Human Nutrition and Division of Epidemiology and Biostatistics, University of Illinois at Chicago \\ (UIC), 1919 W. Taylor Street, Chicago, IL 60612, USA: ${ }^{2}$ Institute of Nutrition and Food Hygiene, Chinese Academy \\ of Preventive Medicine, Beijing, People's Republic of China: ${ }^{3}$ Department of Nutrition and Carolina Population \\ Center, University of North Carolina, Chapel Hill, NC, USA
}

Submitted 19 August 2002: Accepted 6 March 2003

\begin{abstract}
Objective: To study the dynamics of childhood overweight and the influence of dietary intake on tracking of overweight. Design and setting: A follow-up study conducted in China.

Subjects: Ninety-five overweight children, 6-13 years old, identified from 1455 children at baseline, were followed over a 2-year period.

Methods: Data on anthropometry and 3-day dietary intake were collected at baseline and during follow-up. Overweight was defined using the International Obesity Task Force reference of body mass index (BMI)-for-age. Differences between groups were tested using analysis of variance and Cochran-Mantel-Haenszel tests.

Results: Of the 95 overweight children, 36.8\% remained overweight 2 years later ('tracking group'). Urban boys were three times more likely than rural boys to remain overweight (63.2\% vs. 21.9\%). At baseline, the tracking group had higher BMI, body weight and fat intake ( $\%$ of energy), and lower carbohydrate intake ( $\%$ of energy), than the non-tracking group (who shifted from overweight to not overweight); they were more likely to have a high-fat or high-meat diet, but less likely to have a diet high in carbohydrate or vegetables and fruit. During the follow-up, the tracking group increased fat intake and reduced carbohydrate intake while the non-tracking group did not; and they also grew slower in height but faster in weight. Tracking of overweight seemed to be related to tracking of high-meat (relative risk (RR) 2.4, 95\% confidence interval (CI) 1.0-5.6, $P<0.05$ ) and high-fat (RR 1.5, 95\% CI 0.9-2.5, $P<0.1)$ diets.

Conclusion: Considerable changes in children's overweight status during childhood and adolescence were observed in China, a transitional society. Dietary patterns, particularly dietary composition, seemed to influence the tracking patterns of overweight.
\end{abstract}

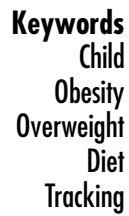

Obesity has become a global epidemic ${ }^{1-3}$. Childhood and adolescence are identified as two critical periods for the development of obesity ${ }^{4}$, and extensive efforts have begun to focus on the prevention and management of obesity during this period ${ }^{5}$. Numerous studies from industrialised countries have shown that large proportions of obese children remain obese through adolescence and into adulthood ${ }^{6-8}$. Most previous research has focused on investigating the risk factors for the development of obesity - studying why non-obese individuals become obese. Few studies based on free-living populations

†Preliminary results were presented at the Federation of American Societies for Experimental Biology (FASEB) 2001 Conference held at Orlando, FL, USA in April 2001. have examined why obese children have different body weight status at older ages, although some small-scale intervention studies have tested the effects of vigorous behaviour and lifestyle modification efforts ${ }^{9-12}$. Such studies will provide useful insights into the development of effective programmes, particularly for preventing overweight children from becoming obese adults.

Another major gap in the literature is the lack of understanding of the effects of childhood diet on obesity $^{13}$. Although dietary intake is widely viewed as a crucial determinant of obesity, to our knowledge only limited longitudinal studies have examined this topic in free-living children, and findings are inconclusive ${ }^{13-17}$. Many previous studies have examined the association between children's dietary intake and body composition 
using cross-sectional data, which cannot test causality ${ }^{18}$. Positive energy balance is the fundamental biological basis for obesity ${ }^{1,19}$. Surprisingly, very few studies have detected a positive relationship between energy intake and fatness, particularly in studies conducted in industrialised countries ${ }^{13}$. Underreporting and other measurement errors are suggested as possible explanations for the failure to detect these associations ${ }^{20-22}$. In a comprehensive meta-analysis, Parsons et al. ${ }^{13}$ concluded that findings about the effects of various dietary factors are inconclusive, and current literature provides little evidence to suggest a relationship between any aspect of childhood diet and fatness in adulthood in industrialised countries. It is argued that the relationship between dietary intake and body composition may be more complex than what is indicated by a simple model of energy balance ${ }^{23,24}$. Increasing evidence from studies, mainly in adults, suggests that diet composition influences food and energy intakes and affects adiposity ${ }^{23-27}$.

This study examined the dynamic patterns of overweight among Chinese children and their predictors. We focused on the influence of dietary intake on tracking of overweight. Longitudinal data from the China Health and Nutrition Survey (CHNS) were used. Over the past two decades, China, while undergoing extremely rapid socioeconomic changes, has become a society where people's living standards, lifestyles, diet and nutritional status are highly heterogeneous ${ }^{28-30}$. This provides an excellent setting for enhancing our understanding of the aetiology of childhood obesity.

\section{Materials and methods}

\section{Study design}

The CHNS was a longitudinal study initiated in 1989 in eight provinces that vary substantially in geography, economic development, public resources and health indicators. Data have been collected in four rounds (in 1989, 1991, 1993 and 1997). The initial survey covered 3780 households from 192 communities, totalling 16000 individuals. School-aged children have been included since 1991. More details about the study design and data collection are provided elsewhere ${ }^{31}$.

\section{Subjects}

Our analysis focused on 95 children who were initially overweight at baseline (1991) and were resurveyed in 1993. These children were identified from 1455 participants, aged 6-13 years in 1991, who had completed data in the 1991 and 1993 surveys. At baseline 1535 children had completed anthropometric measures. Individuals were lost to follow-up mainly because of physical absence when the later surveys were conducted, e.g. being away from home due to attending school, working or visiting relatives. Our analysis shows that the children's main baseline sociodemographic characteristics such as age, sex and urban-rural residence were not significantly different between those who were followed and those who missed the 1993 survey $(P>0.05)$. (Note: the 1997 data were not used in the present study.*) The School of Public Health at the University of North Carolina and the Chinese Academy of Preventive Medicine have reviewed and approved the procedures for the protection of human subjects during data collection.

\section{Data collection}

\section{Anthropometry}

Measurements of body weight, height, triceps skinfold thickness and arm circumference were obtained from all family members (i.e. children and their parents) in each survey. Weight was measured in light, indoor clothing to the nearest $0.1 \mathrm{~kg}$ with a beam balance scale. Height was measured without shoes to the nearest $0.1 \mathrm{~cm}$ using a portable stadiometer.

\section{Dietary data}

Detailed household food consumption data and individual dietary intake data were collected for three consecutive days in each survey. The sample was randomly allocated from Monday to Sunday and almost equally balanced across the seven days of the week from each sampling unit. Household food consumption was determined by inventory change from the beginning to the end of each day. Individual dietary intake data (24-hour recall) for the same three consecutive days were obtained from all family members. For young children (under 10 years), the mothers reported their dietary intake. The collection of data on household food consumption and individual dietary intake allowed a check on the quality of each against the other. At the time of data collection, the individual and household dietary data were compared and used to identify major discrepancies. When significant discrepancies were found, the household and the individual in question were revisited and asked about their food consumption to resolve these discrepancies.

*The 1997 data were not used in the present study because of several considerations. First, one of the eight provinces did not participate in the 1997 survey. As a result, the sample size was reduced considerably in 1997 . Second, only a small number of children $(<15 \%)$ remained overweight in 1997 based on the International Obesity Task Force (IOTF) standard that we used. The small numbers did not allow us to make meaningful comparisons between the two groups. Third, we suspect that the IOTF reference might have a low sensitivity in identifying overweight individuals in older adolescents from developing countries ${ }^{31}$. However, no local body mass index (BMI) reference for child and adolescent overweight is available in China. Finally, increasing evidence shows a close association between sexual maturation and obesity. Our previous research and others found that the median age of menarche among Chinese girls is around 13.7 years. Therefore, to limit our analysis within a 2-year follow-up period (1991 to 1993) for children initially aged 6-13 years would help minimise the influence of puberty and that of other factors listed above. 
From the household dietary data, information on cooking oil and other condiments, such as salt, supplemented the individual dietary intake data based on individuals' amounts of meat and vegetable consumption ${ }^{32,33}$. Great efforts were made in the field to survey all subjects within a short period in the autumn in each survey. The 1991 Chinese food consumption table ${ }^{34}$ was used to calculate subjects' nutrient intakes.

\section{Quality control}

The survey team comprised 20-23 nutritionists for each of the provinces in each round of the survey. All interviewers had at least a college degree and they had attended 10-day training sessions for each survey. Most interviewers had experience of conducting other national health and nutrition surveys. Interviewers were required to follow a carefully developed protocol similar to that used in the US National Health and Nutrition Examination Surveys (NHANES) $^{35}$. In addition, inter- and intra-observer reliability and equipment checks were conducted during the training and data collection.

\section{Measures and study variables}

Definition of overweight

BMI (weight $(\mathrm{kg}) /[\text { height }(\mathrm{m})]^{2}$ ) has been used widely in adults to define overweight and obesity ${ }^{1}$. Currently BMI is increasingly accepted for use in children and adolescents $^{1,36-40}$. We chose to use the IOTF sex-age-specific BMI cut-offs to define child overweight, which corresponds to $\mathrm{BMI}=25 \mathrm{~kg} \mathrm{~m}^{-2}$ at age 18 years $^{37}$. The IOTF reference was developed on the basis of data from six countries world-wide. In addition, if in 1991 a mother or father's BMI was $\geq 25 \mathrm{~kg} \mathrm{~m}^{-2}$, they were classified as overweight; if BMI was $<18.5 \mathrm{~kg} \mathrm{~m}^{-2}$, they were classified as underweight ${ }^{1}$.

\section{Dietary intakes}

Each child's diet was characterised by using his/her 3-day average macronutrient intakes and food group consumption. Two main food groups, meats and vegetables and fruit (VF), were selected based on the University of North Carolina-Institute of Nutrition and Food Hygiene China Food Grouping System, which was developed by the authors (Wang et al., 1998, unpublished). The Food Grouping System separates over 1400 foods into five major categories (i.e. (1) grains, cereals and products; (2) vegetables and fruits; (3) animal source products; (4) cooking oil, seasoning and other condiments; and (5) other) and 39 food groups (e.g. the VF category was further divided into seven groups including fresh vegetables, fresh fruits, dried vegetables, pickled vegetables, etc.). Meats and VF were highlighted in this study because they are likely to influence the energy density of an individual's diet and total energy intake (TEI), and thus affect adiposity. Meats included red meats such as pork, beef and lamb, poultry, game, organ meats, fish and meat products. Note that, in general, fruit consumption in China is quite low, especially in rural areas ${ }^{29}$. Thus, vegetables were the major component of the sample's VF consumption.

We chose to use 'relative measures' (e.g. proportion of TEI derived from a certain macronutrient) instead of absolute measures (e.g. amount of nutrient or food intake) to study the effects of dietary intake on overweight over time. This is because biological requirements for nutrients and energy keep changing with age during childhood and adolescence, and also vary by sex and maturation status $^{41,42}$. Furthermore, increasing evidence suggests that the composition of the diet affects adiposity, although very few studies have found a positive relationship between TEI and obesity ${ }^{13}$.

We computed children's TEI as a 'percentage of the Chinese Recommended Dietary Allowances (RDA) (\%RDA), ${ }^{34}$, along with dietary fat and carbohydrate intakes as 'percentages of energy (\%E) from each of these macronutrients' (see Table 1). Moreover, because the Chinese RDA for energy intake is provided only for age groups for children (see Appendix) and because biological energy requirements vary by body size, children's TEI was also expressed as 'energy/height' $\left(=\mathrm{kcal} \mathrm{cm}^{-1}, 1 \mathrm{kcal}=4.184 \mathrm{~kJ}\right)$. Note that height but not weight was used, because the outcome variable in the present study was obesity. Consumption of meats and VF was measured as 'grams per $1000 \mathrm{kcal}$ ' $\left(\mathrm{mg} \mathrm{kcal}^{-1}\right)$. We focused on examining the structure of the children's diet instead of absolute amounts of dietary intake. Such energy adjustment also allowed for addressing reporting errors and bias ${ }^{43}$. Several special types of dietary intake patterns were defined and are presented in Table 1 .

\section{Data analysis}

Based on children's BMI, we first examined the dynamic patterns of their overweight status between 1991 and 1993. Then, we compared the differences between the overweight tracking and non-tracking groups (Groups 1 and 2, see below). We attempted to examine: (1) whether they had different baseline characteristics; and (2) whether they had experienced different changes during the follow-up. Based on individuals' BMI measures in 1991 and 1993, children were separated into four groups (representing four types of dynamic pattern):

- Group 1: overweight $\rightarrow$ overweight group (tracking of overweight);

- Group 2: overweight $\rightarrow$ non-overweight (non-tracking of overweight);

- Group 3: non-overweight $\rightarrow$ overweight (development of overweight); and

- Group 4: non-overweight $\rightarrow$ non-overweight (not overweight in either year). 
Table 1 Measures of main dietary intakes and definitions of several dietary intake patterns

\begin{tabular}{|c|c|}
\hline Dietary intakes & Definitions/measures \\
\hline \multicolumn{2}{|l|}{ Baseline dietary intake patterns } \\
\hline \multicolumn{2}{|c|}{ 1. Dietary intakes as continuous variables } \\
\hline Energy $\left(\mathrm{kcal} \mathrm{cm}{ }^{-1}\right.$ or \%RDA) & $\begin{array}{l}\text { Total energy intake was expressed as calories/height } \\
\left(=\mathrm{kcal} \mathrm{cm}^{-1}\right) \text { and as } \% \text { of the Chinese RDA }\end{array}$ \\
\hline Fat $(\% \mathrm{E})$ & As $\%$ of total energy derived from fat \\
\hline $\mathrm{CHO}(\% \mathrm{E})$ & As $\%$ of total energy derived from $\mathrm{CHO}$ \\
\hline Meat $\left(\mathrm{mg} \mathrm{kcal}^{-1}\right)^{*}$ & As grams of meat per $1000 \mathrm{kcal}$ of total energy intake \\
\hline $\mathrm{VF}\left(\mathrm{mg} \mathrm{kcal}^{-1}\right)^{*}$ & As grams of VF per $1000 \mathrm{kcal}$ of total energy intake \\
\hline \multicolumn{2}{|c|}{ 2. Dietary intakes as categorical variables (types of diet) } \\
\hline High-energy diet & Total energy intake $>120 \%$ Chinese RDA \\
\hline High-fat diet & $\%$ of energy derived from dietary fat $>30 \%$ \\
\hline High-CHO diet & $\%$ of energy derived from $\mathrm{CHO}>70 \%$ \\
\hline High-meat diet & Meat consumption in the top quartile \\
\hline High-VF diet & VF consumption in the top quartile \\
\hline
\end{tabular}

Dietary intake patterns during the follow-up (time 1 and time 2)

3. Change in dietary intakes

Change in energy, fat, $\mathrm{CHO}$, meat, and VF intakes $\quad$ Change $=($ intake at time 2$)-($ intake at time 1)

4. Tracking of diet types

Tracking of a high-energy diet

Tracking of a high-fat diet

Tracking of a high-CHO diet

Tracking of a high-meat diet

Tracking of a high-VF diet

Maintenance of total energy intake $>120 \%$ Chinese RDA

Maintenance of $\%$ of total energy from fat $>30 \%$

Maintenance of $\%$ of total energy from $\mathrm{CHO}>70 \%$

Maintenance of meat consumption in the top quartile

Maintenance of VF consumption in the top quartile

RDA - Recommended Dietary Allowance; E - energy; CHO - carbohydrate; VF - vegetables and fruit.

${ }^{*} 1 \mathrm{kcal}=4.184 \mathrm{~kJ}$

We focused on comparing the first two groups, but not the last two, because a large body of literature has studied the risk factors for the development of obesity.

We conducted Cochran-Mantel-Haenszel tests to examine the differences in categorical variables. Relative risk (RR) and 95\% confidence interval (CI) are presented. Logistic regression analysis could not be performed owing to small sample size ${ }^{44}$. For continuous variables, we conducted analyses of variance using General Linear Models to test the differences between groups, adjusted for age and gender. Next, using Cochran-MantelHaenszel tests we studied the association between tracking of overweight and tracking of dietary intake patterns. Finally, similar analyses were performed to compare the two groups' experience during the follow-up (i.e. changes in dietary intake and growth in height and weight). Note that we also considered more completely specified models, which included a number of thesis variables simultaneously. But we chose not do this due to: (1) our small sample size; and (2) some of the variables being highly correlated, e.g. the correlation coefficient $(r)$ between baseline fat and carbohydrate intakes was 0.99; and $r=0.37$ for BMI and weight. Furthermore, collinearity was detected when the dietary intake variables were all included. A separate concern relates to the possible need of adjustments for multiple comparisons. These adjustments were not made because they are recommended for clinical trials, but not for observational epidemiological studies ${ }^{45-49}$. Data management and data analysis were performed using SAS software, version 8.2 (SAS Institute Inc., Cary, NC, USA).

\section{Results}

\section{Main characteristics of the sample and overweight dynamics patterns}

At baseline, the mean age of the sample was 9.4 (standard deviation (SD) 2.2) years, 51.8\% were aged 6-9 years and $48.2 \%$ were aged $10-13$ years. Their mean BMI was 16.2 (SD 3.1) $\mathrm{kg} \mathrm{m}^{-2} ; 47.2 \%$ were female, and $24.1 \%$ lived in urban areas. Cross-sectional analysis revealed that the prevalence of overweight was 6.4\% in 1991 and $6.3 \%$ in 1993 . During $1991-1993$, only a small proportion $(4.2 \% ; 57 / 1360)$ of non-overweight children became overweight.

Table 2 Overweight tracking patterns (\% of tracking), by gender, age, residence and family income $†$

\begin{tabular}{lccc}
\hline Characteristic & All $(n=95)$ & Boys $(n=51)$ & Girls $(n=44)$ \\
\hline All & 36.8 & 37.3 & 36.4 \\
Age (years) & & & \\
$\quad 6-9$ & 42.4 & 44.1 & 40.6 \\
$\quad$ 10-13 & 24.1 & 23.5 & 25.0 \\
Residence & & & \\
$\quad$ Rural & 30.4 & $21.9^{*}$ & 37.8 \\
$\quad$ Urban & 53.9 & $63.2^{*}$ & 28.6 \\
Family income & & 31.3 & 29.2 \\
$\quad$ Low & 30.0 & 35.0 & 50.0 \\
$\quad$ Medium & 39.3 & 46.7 & 41.7 \\
$\quad$ High & 44.4 & & \\
\hline
\end{tabular}

†Overweight was defined based on the International Obesity Task Force body mass index (BMI) cut-off point, which corresponds to $\mathrm{BMI}=$ $25 \mathrm{~kg} \mathrm{~m}^{-2}$ at age 18 years ${ }^{37}$.

$\ddagger$ Per capita family income, tertile.

${ }^{*}$ The difference was statistically significant, $P<0.05$. 
The overweight tracking patterns are presented in Table 2. Over one-third (36.8\%) of the 95 overweight children remained overweight in 1993. Overweight children (6-9 years) were more likely to remain overweight than were adolescents (10-13 years). Urban boys were almost three times more likely to remain overweight than their rural counterparts (63.2\% vs. $21.9 \%, P<0.05)$. In contrast, urban overweight girls were less likely to remain overweight than rural girls, but the difference (28.6\% vs. $37.8 \%)$ was not significant $(P>0.05)$.

\section{Comparison of baseline characteristics between the overweight tracking and non-tracking groups}

As shown in Table 3, the overweight tracking group had a significantly higher $\% \mathrm{E}$ derived from dietary fat intake (23.6\% vs. 19.1\%), but a lower \%E from carbohydrate (64.0\% vs. 68.9\%). They also had higher meat consumption but lower VF consumption, although the differences between the two groups were not significant $(P>0.05)$. The tracking group was heavier and had higher BMI than the non-tracking group $(P<0.05)$.

We also examined dietary intakes as categorical variables - types of diet (Table 4). Overweight children who had a high-fat diet $(P<0.1)$ or a high-meat diet $(P<0.05)$ were more likely to remain overweight; but those who had a high-carbohydrate diet or a high-VF diet were at a lower risk $(P<0.05)$. Overall, urban children were more likely to remain overweight than their rural counterparts $(P<0.05)$, which was primarily due to the urban-rural difference for boys.

\section{Linkage between tracking of overweight and tracking of dietary intake patterns}

Cochran-Mantel-Haenszel tests reveal that tracking of overweight was associated with the tracking of dietary intake patterns. Children who maintained a high-meat diet (RR 2.4, 95\% CI 1.0-5.6, $P<0.05$ ) or a high-fat diet (RR $1.5,95 \%$ CI $0.9-2.5, P<0.1$ ) were more likely to remain overweight. Note that if odds ratios (ORs) were reported, they were much greater then RRs; e.g. for tracking of high-meat diet, OR and 95\% CI were 4.4 and $1.0-19.6$.

\section{Comparison of changes in dietary intake during the follow-up between the overweight tracking and non-tracking groups}

Although none of the differences in dietary intake changes between the two groups were statistically significant when adjusted for age and gender $(P>0.05)$, compared with the non-tracking group, the overweight tracking group had a smaller decrease in TEI levels, expressed as \%RDA $(-13.0$ vs. -18.1$)$ and as a measure relative to children's height $(-1.9$ vs. -3.7$)$, and a greater increase in meat consumption $\left(6.8 \mathrm{mg} \mathrm{kcal}^{-1}\right.$ vs. $\left.0.9 \mathrm{mg} \mathrm{kcal}^{-1}\right)$, which is marginally significant $(P<0.07)$.

As shown in Table 5, when children's baseline BMI and corresponding baseline dietary intake were also adjusted, the differences in fat and carbohydrate intakes between the two groups became significant $(P<0.05)$. The tracking group had increased their fat intake and decreased carbohydrate intake, while the non-tracking group decreased their fat intake and increased carbohydrate intake. In addition, the tracking group's meat consumption increased, but the non-tracking group's was almost not changed.

\section{Difference in growth patterns between the overweight tracking and non-tracking groups}

The overweight tracking group grew faster in weight but slower in height than the non-tracking group during the

Table 3 Comparison of baseline characteristics (expressed as mean (SE)) between the overweight tracking and non-tracking groups continuous variables†

\begin{tabular}{|c|c|c|c|}
\hline Characteristic & $\begin{array}{l}\text { Non-tracking group } \\
\quad(n=60)\end{array}$ & $\begin{array}{l}\text { Tracking group } \\
\quad(n=35)\end{array}$ & $\begin{array}{l}\text { Significance of the adjusted } \\
\text { difference ( } P \text {-value })\end{array}$ \\
\hline \multicolumn{4}{|l|}{ Dietary intakes } \\
\hline Energy (\%RDA) & $118.2(4.2)$ & $113.5(5.5)$ & \\
\hline Energy $\left(\mathrm{kcal} \mathrm{cm}{ }^{-1}\right) \ddagger$ & $19.1(0.7)$ & $17.6(1.0)$ & \\
\hline Fat $(\% \mathrm{E})$ & $19.1(1.6)$ & $23.6(2.1)$ & $\star *$ \\
\hline $\mathrm{CHO}(\% \mathrm{E})$ & $68.9(1.6)$ & $64.0(2.1)$ & ** \\
\hline Meat $\left(\mathrm{mg} \mathrm{kcal}^{-1}\right) \S$ & $18.1(3.3)$ & $23.1(4.3)$ & \\
\hline $\operatorname{VF}\left(\mathrm{mg} \mathrm{kcal}^{-1}\right) \S$ & $130.8(12.1)$ & $109.5(15.8)$ & \\
\hline \multicolumn{4}{|l|}{ Other characteristics } \\
\hline Age (years) & $8.8(0.3)$ & $8.4(0.3)$ & \\
\hline $\begin{array}{l}\text { Per capita family income } \\
\text { (Chinese Yuan, deflated) }\end{array}$ & 926.3 (123.5) & $1073.6(160.3)$ & \\
\hline BMI $\left(\mathrm{kg} \mathrm{m}^{-2}\right)$ & $21.9(0.4)$ & $23.5(0.6)$ & ** \\
\hline Height $(\mathrm{cm})$ & $122.5(2.0)$ & $126.0(2.6)$ & \\
\hline Weight (kg) & $32.6(1.2)$ & $36.0(1.5)$ & ** \\
\hline
\end{tabular}

SE - standard error; RDA - Recommended Dietary Allowance; E - energy; CHO - carbohydrate; VF - vegetables and fruit; BMI - body mass index. † Least-square means (SE) were calculated based on analysis of variance of General Linear Models. Age and gender were adjusted. The analysis was conducted for each baseline characteristic separately.

$\ddagger$ To address the difference in energy requirement by body size, children’s energy intake relative to height $(\mathrm{cm})$ was examined.

$\S 1 \mathrm{kcal}=4.184 \mathrm{~kJ}$

${ }^{\star \star} P<0.05$. 
Table 4 Comparison of baseline characteristics (expressed as RR $(95 \% \mathrm{Cl})$ ) between the overweight tracking and non-tracking groups - categorical variables†

\begin{tabular}{llc}
\hline Characteristic & $\mathrm{RR}(95 \% \mathrm{Cl})$ & $P$-value \\
\hline Dietary intakes $\ddagger$ & & \\
High-energy diet & $0.8(0.6-1.1)$ & \\
High-fat diet & $1.5(1.0-2.2)$ & $*$ \\
High-CHO diet & $0.7(0.5-0.9)$ & $*$ \\
High-meat diet & $1.7(1.0-2.7)$ & $* \star$ \\
High-VF diet & $0.7(0.5-0.9)$ & $*$ \\
Other characteristics & $1.0(0.7-1.4)$ & \\
Female & $0.8(0.6-1.0)$ & $*$ \\
Older age (10-13 years)§ & $1.5(1.1-2.3)$ & $* \star$ \\
Urban & $1.4(0.9-2.0)$ & $*$ \\
Parental overweightף & $1.2(0.6-2.2)$ & \\
Parental underweight & \\
\hline
\end{tabular}

$\mathrm{RR}$ - relative risk; $\mathrm{Cl}$ - confidence interval; $\mathrm{CHO}$ - carbohydrate; VF vegetables and fruit.

†Based on Cochran-Mantel-Haenszel tests. Age and gender were adjusted. The analysis was conducted for each characteristic separately. RR means (e.g. high-fat diet) that overweight children who had a high-fat diet at the baseline were 1.5 times more likely to remain overweight than those children who did not.

$\ddagger$ Definitions are provided in Table 1.

$\S$ Only gender was adjusted.

9 Parental overweight was defined as $\mathrm{BMI} \geq 25 \mathrm{~kg} \mathrm{~m}^{-2}$ and underweight as $\mathrm{BMI}<18.5 \mathrm{~kg} \mathrm{~m}^{-2}$. Father's overweight was marginally statistically significant $(P<0.1)$, RR $(95 \% \mathrm{Cl}): 1.5(1.0-2.4)$.

${ }^{\star}, P<0.1 ;{ }^{*}, P<0.05$.

follow-up (Fig. 1). The ratio of growth in weight-to-height was 0.9 vs. 0.2. We also compared these two groups with the other two groups (those who initially were not overweight). The overweight tracking group had a similar height growth rate to those who remained non-overweight. Non-overweight children who became overweight in 1993 grew slower in height but faster in weight than the other three groups. These suggest that growth patterns and sexual maturation may influence children's risk of remaining overweight.

\section{Discussion}

Studies conducted in industrialised countries show that approximately one-third of obese children and one-half of obese adolescents remain obese as adults, but the rate varies considerably between studies ${ }^{6,7}$. In general, obesity tracking patterns seem to be influenced by the length of follow-up, definitions of obesity, initial age when obesity developed, degree of initial obesity status, social environmental factors and genetic disposition ${ }^{6,7}$. Following 95 overweight children in China, a society under rapid socio-economic transitions, we found that only over onethird of children remained overweight over a 2-year period. Our results are consistent with Mo-suwan et al.'s findings in Thailand ${ }^{50}$. They reported that $12 \%$ of children remained overweight over a 5 -year period. They defined overweight using the 85th percentile of BMI derived from the US NHANES I data ${ }^{36}$. These findings may suggest considerable opportunities to help reverse overweight children's body weight status.

Several factors may help explain the low tracking in overweight we observed. First, this may be due to the rapid changes in socio-economic factors and people's lifestyles in China over the past two decades ${ }^{28,30}$. Overweight children might have changed their lifestyles considerably during the follow-up as a result of the changes in their environments. Second, we used the IOTF reference to define overweight, which might have underestimated the tracking proportion. Previous findings from other studies and ours indicate that applying references based on data from wealthy populations in developing countries may be problematic, especially for longitudinal studies $31,36,51-53$. The IOTF reference as well as the WHO reference ${ }^{36}$ used by Mo-suwan et al. in their tracking study ${ }^{50}$ may have a lower sensitivity for identifying overweight individuals among adolescents than among children in developing countries $^{51,52}$. Moreover, the phenomenon may also be related to the high prevalence of stunting among Chinese children at young ages ${ }^{54}$. Stunting is suggested as a risk factor for childhood obesity ${ }^{55,56}$. We suspect that catch-up growth occurring at older ages, well-documented previously $^{57}$, may have helped reverse some children's overweight status. Nevertheless, our findings indicate that environmental and behavioural factors affect one's risk of remaining overweight.

Table 5 Comparison of changes in dietary intake (expressed as mean (SE)) during the follow-up (1991-1993) between the overweight tracking and non-tracking groups: adjusted for baseline BMI and corresponding dietary intake†

\begin{tabular}{|c|c|c|c|c|}
\hline $\begin{array}{l}\text { Change during the } \\
\text { follow-up } \neq\end{array}$ & $\begin{array}{l}\text { Non-tracking group } \\
\quad(n=60)\end{array}$ & $\begin{array}{l}\text { Tracking group } \\
\quad(n=35)\end{array}$ & $\begin{array}{c}\text { Difference } \\
(=\text { 'tracking' - 'non-tracking') }\end{array}$ & $\begin{array}{l}\text { Significance of the difference } \\
(P \text {-value })\end{array}$ \\
\hline Energy (\%RDA) & $-23.2(6.1)$ & $-13.1(6.9)$ & 10.1 & \\
\hline Energy $\left(\mathrm{kcal} \mathrm{cm}^{-1}\right) \S \rrbracket$ & $-4.3(1.0)$ & $-2.7(1.1)$ & 1.6 & \\
\hline Fat (\%E) & $-1.7(1.8)$ & $4.9(2.5)$ & 6.6 & $\star \star \star$ \\
\hline $\mathrm{CHO}(\% \mathrm{E})$ & $1.5(1.7)$ & $-4.4(2.2)$ & -5.9 & ** \\
\hline Meat $\left(\mathrm{mg} \mathrm{kcal}^{-1}\right)$ q & $-1.3(4.6)$ & $10.9(5.6)$ & 12.2 & * \\
\hline $\operatorname{VF}\left(\mathrm{mg} \mathrm{kcal}^{-1}\right) q^{\prime}$ & $-25.5(18.5)$ & $-15.5(21.2)$ & 10.0 & \\
\hline
\end{tabular}

SE - standard error; BMI - body mass index; RDA - Recommended Dietary Allowance; E - energy; CHO - carbohydrate; VF - vegetables and fruit.

† Least-square means (SE) were calculated based on analysis of variance of General Linear Models. Age, gender, baseline BMI and corresponding baseline dietary intake were adjusted. The analysis was conducted for each characteristic separately. $\ddagger$ Change $=$ (follow-up measure) - (baseline measure).

$\S$ To address the difference in energy requirement by body size, children's energy intake relative to height $(\mathrm{cm})$ was examined. I $1 \mathrm{kcal}=4.184 \mathrm{~kJ}$.

${ }^{\star}, P<0.1 ;{ }^{* *}, P<0.05$. 


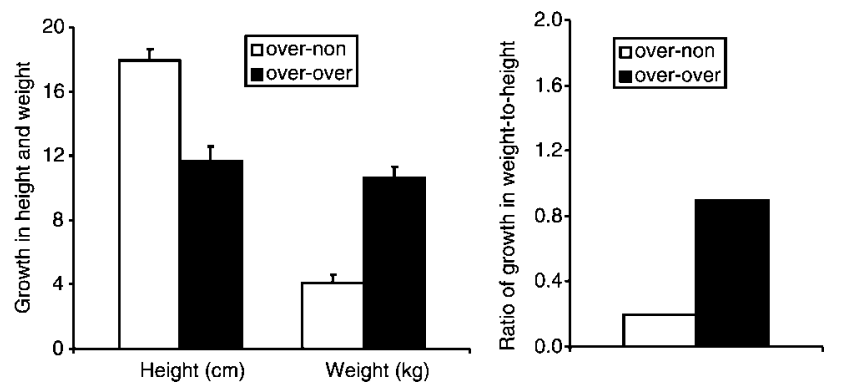

Fig. 1 Differences in growth patterns between overweight tracking (over-over) and non-tracking (over-non) groups. Growth rates were least-square means (bars, standard error) calculated based on analysis of General Linear Models, and age and gender were adjusted; all differences were statistically significant $(P<0.05)$. Growth ratios were calculated based on the means of growth in height $(\mathrm{cm})$ and weight $(\mathrm{kg})$

We found that children who remained overweight over time had different baseline characteristics and experiences during the follow-up. Dietary intake related to the tracking of overweight. Children who tracked overweight were more likely to have a higher baseline fat intake but lower carbohydrate intake; and were more likely to have a highmeat diet, but less likely to have a high-carbohydrate or high-VF diet. Overweight children who tracked high-fat and high-meat diets were more likely to remain overweight. It is likely that the associations may be even stronger than what we observed if intra-individual variations in dietary intake can be corrected ${ }^{43,58}$

Although energy balance in particular is the fundamental biological basis for the influence of diet on obesity, we did not observe a significant association between energy intake and tracking of overweight. There are several possible explanations. First, our small sample size $(n=95)$ did not provide us with adequate statistical power. Second, we could not adjust for children's physical activity, which may be a potential confounder. Third, these overweight children might have changed their energy intake during the follow-up as indicated by our data. For example, we found that both the tracking and nontracking groups reduced their TEI relative to the Chinese RDA and their body size, but the tracking group reduced less than the non-tracking group. Finally, similar to many other studies conducted in free-living populations, we could not measure children's TEI accurately, while measures of diet composition (e.g. \%E from fat) may be a better indicator of children's actual energy intake levels. We think that the composition of the sample's diets will be more accurate or reliable than their reported absolute amounts of foods/nutrients consumed. Goldberg and colleagues reported that the majority of previous nutritional epidemiological studies that used 24-hour recalls have underestimated individuals' $\mathrm{TEI}^{59}$. Energy adjustment generally reduces measurement error ${ }^{43}$

Our data suggest an association between fat intake and tracking of overweight. A number of mechanisms have been suggested to explain why higher fat intake is linked with obesity ${ }^{23-26,60}$. First, individuals who consume a high-fat (as \%E from fat) diet are likely to have higher TEI. Second, excess energy from fat can readily be stored in body adipose tissue depots with very high efficiency. For example, about $96 \%$ of excess energy from fat but only $60-80 \%$ from carbohydrate may be stored as body fat. This also helps explain why our subjects who had higher carbohydrate intakes were less likely to track overweight. Recently, based on clinical trials conducted between 1966 and 1998, Astrup et al. $^{23}$ concluded that a reduction in dietary fat intake without restriction of TEI prevents weight gain in subjects of normal weight and produces a weight loss in overweight subjects.

The linkage between meat consumption and tracking of overweight is likely related to the impact of diet composition on TEI. Children who consume more meat are likely to have a higher TEI due to the higher energy density and fat content of their diets. Pork is the main type of meat consumed in China, which usually has a high fat content $^{29}$. But we suggest that people should be cautious to recommend reducing children's meat consumption in developing countries like China, where a large proportion of the population do not have adequate protein intake and suffer from a range of nutrition deficiencies ${ }^{29,54}$. In these populations, higher meat consumption will help the children obtain adequate amounts of the high-quality protein, vitamins and minerals needed for growth and development ${ }^{41,42}$.

The study of tracking of obesity in children and adolescents is complicated by their complex linear growth patterns. Few studies have examined the linkage between tracking of obesity and children's linear growth patterns. Previously, De Simone et al. reported that obese subjects had a less notable growth spurt during puberty than lean children $^{61}$. Falorni et al. ${ }^{62}$ found that, compared with nonobese children, obese Italian children had a significantly greater height velocity before puberty; but around the age of puberty, their growth spurt was reduced and more precocious. As a result, obese children were shorter than non-obese individuals. These obese children had participated in a weight-reduction programme. It is less clear whether such findings are applicable to free-living children, but previous evidence suggests that children's linear growth is not influenced by the treatment of obesity $^{63}$. Based on longitudinal data collected for a large Swedish cohort of children $(n=3650)$, He and Karlberg recently reported a positive association between BMI gain and height gain during childhood (2-8 years); but BMI gain during childhood was associated with reduced height gain in adolescence. However, they found no direct correlation between BMI gain in childhood and final height at age 18 years ${ }^{64}$.

We found that, during the follow-up, the tracking group grew faster in weight but slower in height than the non-tracking group. The ratio of growth in weight-toheight was 0.9 vs. 0.2 for the two groups. The high ratio 
of weight-to-height growth for the tracking group was not due to a subnormal growth in height. In fact, we found that the tracking group had a similar height growth rate to nonoverweight children. Rather, it was children who were not overweight at baseline but became overweight who grew slower in height but faster in weight than all the others. This suggests that the growth patterns accompanying sexual maturation during late childhood and adolescence may influence children's risk of having different overweight outcomes, although causality cannot be proved with our data. A large body of literature shows that sexual maturation is related to obesity ${ }^{65-70}$. The complex causal relationship between maturation and fatness is yet to be unravelled but clearly merits further examination.

The present study has several limitations. First, data on physical activity were not collected and, as a result, we were unable to examine how physical activity may influence tracking of overweight. Second, only 95 children were overweight at baseline and could be studied. The small sample size limits our statistical power to detect some significant results. For example, our sample size allows for detecting a significant difference of $17.6 \mathrm{mg} \mathrm{kcal}^{-1}$ in meat consumption and $-64.5 \mathrm{mg} \mathrm{kcal}^{-1}$ in VF consumption between the tracking and non-tracking groups, while the observed differences were 5.0 and $-21.3 \mathrm{mg} \mathrm{kcal}^{-1}$, respectively. Third, the use of BMI and the IOTF reference to classify overweight might have caused some misclassifications. Finally, we could not examine how genetic factors might influence tracking of overweight. It will be of interest to understand the role played by the interaction between genetics and environmental factors ${ }^{19}$.

In conclusion, despite considerable changes in children's overweight status during childhood and adolescence and equally remarkable shifts in diet and socioeconomic factors, the dietary intake patterns of Chinese children appear to influence the dynamics of childhood overweight. Further studies based on larger samples and longer follow-up periods are needed before being able to extrapolate from our findings to the broader context.

\section{Acknowledgements}

This study was supported in part by grants from the National Institutes of Health (NIH) (R01-HD30880 and R01-HD38700) and the Fogarty International Center (TW/HD00633). The China Health Nutrition Survey (CHNS) study is a collaborative research project between the Carolina Population Center (CPC) of the University of North Carolina at Chapel Hill (UNC-CH) and the Chinese Academy of Preventive Medicine (CAPM). Parts of the project design, data collection and computerisation have been funded by the CAPM, UNC-CH and CPC and NIH. We are grateful to Drs Linda Adair, Peggy Bentley, Jianwen Cai and June Stevens for their valuable comments and suggestions.

\section{References}

1 World Health Organization (WHO). Obesity: Preventing and Managing the Global Epidemic. Report of a WHO Consultation. WHO Technical Report Series No. 894. Geneva: WHO, 2000.

2 Wang Y, Monteiro C, Popkin BM. Trends of obesity and underweight in older children and adolescents in the United States, Brazil, China and Russia. American Journal of Clinical Nutrition 2002; 75: 971-97.

3 Popkin BM, Doak CM. The obesity epidemic is a worldwide phenomenon. Nutrition Reviews 1998; 56: 106-14.

4 Dietz WH. Critical periods in childhood for the development of obesity. American Journal of Clinical Nutrition 1994; 59 955-9.

5 Dietz WH, Gortmaker SL. Preventing obesity in children and adolescents. Annual Review of Public Health 2001; 22: 337-53.

6 Power C, Lake JK, Cole TJ. Measurement and long-term health risks of child and adolescent fatness. International Journal of Obesity 1997; 21: 507-26.

7 Serdula MK, Ivery D, Coates RJ, Freedman DS, Williamson DF, Byers T. Do obese children become obese adults? Preventive Medicine 1993; 22: 167-77.

8 Whitaker RC, Wright JA, Pepe MS, Seidel KD, Dietz WH Predicting obesity in young adulthood from childhood and parental obesity. New England Journal of Medicine 1997; 337: 869-73.

9 Epstein LH, Valoski A, Wing RR, McCurley J. Ten-year outcomes of behavioral family-based treatment for childhood obesity. Health Psychology 1994; 13: 373-83.

10 Epstein LH. Family-based behavioural intervention for obese children. International Journal of Obesity 1996; 20(Suppl. 1): S14-21

11 Lytle LA, Stone EJ, Nichaman MZ, Perry CL, Montgomery $\mathrm{DH}$, Niklas TA, et al. Changes in nutrient intakes of elementary school children following a school-based intervention: results from the $\mathrm{CATCH}$ Study. Preventive Medicine 1996; 25: 465-77.

12 Webber LS, Osganian SK, Feldman HA, Wu M, McKenzie TL, Nichaman $\mathrm{M}$, et al. Cardiovascular risk factors among children after a 2 1/2-year intervention - The CATCH Study. Preventive Medicine 1996; 25: 432-41.

13 Parsons TJ, Power C, Logan S, Summerbell CD. Childhood predictors of adult obesity: a systematic review. International Journal of Obesity 1999; 23(Suppl. 8): S1-107.

14 Klesges RC, Klesges LM, Eck LH, Shelton ML. A longitudinal analysis of accelerated weight gain in preschool children. Pediatrics 1995; 95: 126-30.

15 Maffeis C, Talamini G, Tato L. Influence of diet, physical activity and parents' obesity on children's adiposity: a four-year longitudinal study. International Journal of Obesity 1998; 22: 758-64.

16 Nicklas TA. Dietary studies of children and young adults (1973-1988): the Bogalusa Heart Study. American Journal of the Medical Sciences 1995; 310(Suppl. 1): S101-8.

17 Rolland-Cachera MF, Deheeger M, Akrout M, Bellisle F. Influence of macronutrients on adiposity development: a follow up study of nutrition and growth from 10 months to 8 years of age. International Journal of Obesity 1995; 19: 573-8.

18 Rothman KJ, Greenland S. Modern Epidemiology, 2nd ed Philadelphia, PA: Lippincott-Raven, 1998.

19 Bray GA, Bouchard C, James WPT. Handbook of Obesity New York: Marcel Dekker, 1998.

20 Harrison GG, Galal OM, Ibrahim N, Khorshid A, Stormer A Leslie J, et al. Underreporting of food intake by dietary recall is not universal: a comparison of data from Egyptian and American women. Journal of Nutrition 2000; 130 2049-54. 
21 Carter LM, Whiting SJ. Underreporting of energy intake, socioeconomic status, and expression of nutrient intake. Nutrition Reviews 1998; 56: 179-82.

22 Schoeller DA. How accurate is self-reported dietary energy intake? Nutrition Reviews 1990; 48: 373-9.

23 Astrup A, Ryan L, Grunwald GK, Storgaard M, Saris W, Melanson $\mathrm{E}$, et al. The role of dietary fat in body fatness: evidence from a preliminary meta-analysis of ad libitum low-fat dietary intervention studies. British Journal of Nutrition 2000; 83(Suppl. 1): S25-32.

24 Flatt JP. Dietary fat, carbohydrate balance, and weight maintenance. Annals of the New York Academy of Sciences 1993; 683: 122-40.

25 Hill JO, Melanson EL, Wyatt HT. Dietary fat intake and regulation of energy balance: implications for obesity. Journal of Nutrition 2000; 130(Suppl. 2S): 284S-8S.

26 Blundell JE, Macdiarmid JI. Passive overconsumption. Fat intake and short-term energy balance. Annals of the New York Academy of Sciences 1997; 827: 392-407.

27 Appleby PN, Thorogood M, Mann JI, Key TJ. Low body mass index in non-meat eaters: the possible roles of animal fat, dietary fibre and alcohol. International Journal of Obesity and Related Metabolic Disorders 1998; 22: 454-60.

28 China National Bureau of Statistics. China Statistical Yearbook 1999. Beijing: China Statistical Publishing House, 1999.

29 Ge K. The Dietary and Nutritional Status of Chinese Population - Adults (1992 National Nutrition Survey). Beijing: People's Medical Publishing House, 1996.

30 Jing J. Feeding China's Little Emperors: Food, Children, and Social Change. Stanford, CA: Stanford University Press, 2000.

31 Wang Y, Ge K, Popkin BM. Tracking of body mass index from childhood to adolescence: a 6-year follow-up study in China. American Journal of Clinical Nutrition 2000; 72 1018-24.

32 Zhai F, Guo X, Popkin B, Ma L, Qang Q, Yu W, et al. The evaluation of the 24-hour individual recall method in China. Food and Nutrition Bulletin 1996; 17: 154-61.

33 Popkin BM, Lu B, Zhai F. Understanding the nutrition transition: measuring rapid dietary changes in transitional countries. Public Health Nutrition 2002; 5(6A): 947-53.

34 Institute of Nutrition and Food Hygiene, Chinese Academy of Preventive Medicine. Food Composition Table. Beijing: People's Health Press, 1991.

35 US Department of Health and Human Services. Plan and Operation of the Third National Health and Nutrition Examination, Centers for Disease Control and Prevention. The Third National Health and Nutrition Examination Survey (NHANES III 1988-1994) Reference Manuals and Reports [CD-ROM]. Bethesda, MD: National Center for Health Statistics, 1996.

36 World Health Organization (WHO). Physical Status, The Use and Interpretation of Anthropometry. Report of a WHO Expert Committee. WHO Technical Report Series No. 854. Geneva: WHO, 1995.

37 Cole TJ, Bellizzi MC, Flegal KM, Dietz WH. Establishing a standard definition for child overweight and obesity worldwide: international survey. British Medical Journal 2000; 320: 1240-3.

38 Dietz WH, Robinson TN. Use of the body mass index (BMI) as a measure of overweight in children and adolescents. Journal of Pediatrics 1998; 132: 191-3.

39 Himes JH, Dietz WH. Guidelines for overweight in adolescent preventive services: recommendations from an expert committee. The Expert Committee on Clinical Guidelines for Overweight in Adolescent Preventive Services. American Journal of Clinical Nutrition 1994; 59: 307-16.

40 Kuczmarski RJ, Ogden CL, Grummer-Strawn LM, Flegal KM, Guo SS, Wei R, et al. CDC growth charts: United States. Advance Data 2000; 314: 1-27.
41 Mahan LK, Escott-Stump S. Krause's Food, Nutrition, and Diet Therapy, 9th ed. Philadelphia, PA: WB Saunders, 1996.

42 Trahms CM, Pipes PL. Nutrition in Infancy and Childhood, 6th ed. New York: WCB/McGraw Hill, 1997.

43 Willett WC. Nutritional Epidemiology. New York: Oxford University Press, 1998; 273-301.

44 Stokes ME, Davis CS, Koch CG. Categorical Data Analysis using the SAS System. Cary, NC: SAS Institute, Inc., 1995.

45 Bender R, Lange S. Adjusting for multiple testing - when and how? Journal of Clinical Epidemiology 2001; 54: 343-9.

46 Thompson JR. Re: 'Multiple comparisons and related issues in the interpretation of epidemiologic data' [invited commentary]. American Journal of Epidemiology 1998; 147: 801-6, 815 .

47 Rothman KJ. No adjustments are needed for multiple comparisons. Epidemiology 1990; 1: 43-6.

48 Savitz DA, Olshan AF. Multiple comparisons and related issues in the interpretation of epidemiologic data. American Journal of Epidemiology 1995; 142: 904-8.

49 Savitz DA, Olshan AF. Describing data requires no adjustment for multiple comparisons: a reply from Savitz and Olshan. American Journal of Epidemiology 1998; 147: 813-4.

50 Mo-suwan L, Tongkumchum P, Puetpaiboon A. Determinants of overweight tracking from childhood to adolescence: a 5 y follow-up study of Hat Yai schoolchildren. International Journal of Obesity and Related Metabolic Disorders 2000; 24: $1642-7$.

51 Wang Y, Wang JQ, Hesketh T, Qu JD, Mulligan J, Kinra S. Standard definition of child overweight and obesity worldwide [letter]. British Medical Journal 2000; 321: 1158-9.

52 Wang Y, Wang JQ. A comparison of different international references for the assessment of child and adolescent overweight and obesity in different populations. European Journal of Clinical Nutrition 2002; 56: 973-82.

53 Deurenberg P, Yap M. The assessment of obesity: methods for measuring body fat and global prevalence of obesity. Baillières Best Practice \& Research: Clinical Endocrinology \& Metabolism 1999; 13: 1-11.

54 Ge K. The Dietary and Nutritional Status of Chinese Population - Children and Adolescents (1992 National Nutrition Survey). Beijing: People's Medical Publishing House, 1999.

55 Popkin BM, Richards MK, Montiero CA. Stunting is associated with overweight in children of four nations that are undergoing the nutrition transition. Journal of Nutrition 1996; 126: 3009-16.

56 Hoffman DJ, Sawaya AL, Verreschi I, Tucker KL, Roberts SB. Why are nutritionally stunted children at increased risk of obesity? Studies of metabolic rate and fat oxidation in shantytown children from Sao Paulo, Brazil. American Journal of Clinical Nutrition 2000; 72: 702-7.

57 Boersma B, Wit JM. Catch-up growth. Endocrine Reviews 1997; 18: 646-61.

58 Paeratakul S, Popkin BM, Kohlmeier L, Hertz-Picciotto I, Guo X, Edwards LJ. Measurement error in dietary data: implications for the epidemiologic study of the diet-disease relationship. European Journal of Clinical Nutrition 1998; 52: $722-7$

59 Goldberg GR, Black AE, Jebb SA, Cole TJ, Murgatroyd PR, Coward WA, et al. Critical evaluation of energy intake data using fundamental principles of energy physiology: 1. Derivation of cut-off limits to identify underrecording. European Journal of Clinical Nutrition 1991; 45: 569-81.

60 Horton TJ, Drougas H, Brachey A, Reed GW, Peters JC, Hill JO. Fat and carbohydrate overfeeding in humans: different effects on energy storage. American Journal of Clinical Nutrition 1995; 62: 19-29. 
61 De Simone M, Farello G, Palumbo M, Gentile T, Ciuffreda M, Olioso P, et al. Growth charts, growth velocity and bone development in childhood obesity. International Journal of Obesity 1995; 19: 851-7.

62 Falorni A, Galmacci G, Bini V, Faraoni F, Molinari D, Cabiati $\mathrm{G}$, et al. Using obese-specific charts of height and height velocity for assessment of growth in obese children and adolescents during weight excess reduction. European Journal of Clinical Nutrition 1999; 53: 181-8.

63 Epstein LH, McCurley J, Valoski A, Wing RR. Growth in obese children treated for obesity. American Journal of Diseases of Children 1990; 144: 1360-4.

64 He Q, Karlberg J. BMI in childhood and its association with height gain, timing of puberty and final height. Pediatric Research 2001; 49: 244-51.

65 Beunen GP, Malina RM, Lefevre JA, Claessens AL, Renson R, Vanreusel B. Adiposity and biological maturity in girls 6-16 years of age. International Journal of Obesity 1994; 18: $542-6$.

66 Garn SM, LaVelle M, Rosenberg KR, Hawthom VM. Maturational timing as a factor in female fatness and obesity. American Journal of Clinical Nutrition 1986; 43: 879-83.

67 De Ridder CM, Thijssen JHH, Bruning PF, Van den Brande JL, Zonderland ML, Erich WBM. Body fat mass, body fat distribution, and pubertal development: a longitudinal study of physical and hormonal sexual maturation of girls. Journal of Clinical Endocrinology and Metabolism 1992; 75 : 442-6.

68 Van Lenthe FJ, Kemper CG, van Mechelen W. Rapid maturation in adolescence results in greater obesity in adulthood: the Amsterdam Growth and Health Study. American Journal of Clinical Nutrition 1996; 64: 18-24.
69 Adair LS, Gordon-Larsen P. Maturational timing and overweight prevalence in US adolescent girls. American Journal of Public Health 2001; 91: 642-4.

70 Wang Y. Is obesity associated with early sexual maturation? A comparison of the association in American boys versus girls. Pediatrics 2002; 110: 903-10.

\section{Appendix - Chinese Recommended Dietary Allowances for energy intake in children and adolescents}

\begin{tabular}{lccccc}
\hline & \multicolumn{2}{c}{ Boys } & & \multicolumn{2}{c}{ Girls } \\
\cline { 2 - 3 } $\begin{array}{l}\text { Age } \\
\text { (years) }\end{array}$ & $\begin{array}{c}\text { Reference } \\
\text { body weight } \\
(\mathrm{kg})\end{array}$ & $\begin{array}{c}\text { Energy } \\
\text { intake } \\
(\mathrm{kcal})\end{array}$ & & $\begin{array}{c}\text { Reference } \\
\text { body weight } \\
(\mathrm{kg})\end{array}$ & $\begin{array}{c}\text { Energy } \\
\text { intake } \\
(\mathrm{kcal})\end{array}$ \\
\hline $6-$ & 19.8 & 1700 & & 19.1 & 1600 \\
$7-$ & 22.0 & 1800 & & 21.0 & 1700 \\
$8-$ & 23.8 & 1900 & & 23.2 & 1800 \\
$9-$ & 26.4 & 2000 & & 25.8 & 1900 \\
$10-$ & 28.8 & 2100 & & 28.8 & 2000 \\
$11-$ & 32.1 & 2200 & & 32.7 & 2100 \\
$12-$ & 35.5 & 2300 & & 37.2 & 2200 \\
$13-$ & 42.0 & 2400 & 42.4 & 2300 \\
$16-17$ & 54.2 & 2800 & 48.3 & 2400 \\
\hline
\end{tabular}

${ }^{\star}$ Based on reference $34 ; 1 \mathrm{kcal}=4.184 \mathrm{~kJ}$ 